\title{
IMIGRAÇÃO E PERIFERIAS URBANAS: EXPERIÊNCIAS HAITIANAS EM SÃO PAULO
}

\author{
Imigration and urban peripheries: \\ Hatian experiences in São Paulo
}

Erika Andrea Butikofer*
Eliane Alves da Silva**

\begin{abstract}
Resumo. Este artigo discute as formas como imigrantes haitianos se estabelecem nas periferias de São Paulo, tomando o caso particular de Guaianases, distrito do extremo leste da capital paulista. Busca entender as diferentes mediações que operam no estabelecimento desses imigrantes, indagando o quanto essas podem apontar para uma abertura mais ampla de acesso a direitos. A pesquisa se baseia em entrevistas e observação etnográfica e usa como referencial teórico a bibliografia sobre migrações Sul-Sul.
\end{abstract}

Palavras-chave: imigração; Haiti; periferia; São Paulo; Sul Global.

\begin{abstract}
This article discusses the ways in which Haitian immigrants settle on the suburbs of São Paulo taking the case of Guaianases district, in the far east of the capital. It seeks to understand the different mediations present in the access of these immigrants to the city, asking how it can be a possibility to a broader access to the rights. The article is based on interviews and ethnographic observation and uses the bibliography about South-South migrations as a theoretical reference.
\end{abstract}

Keywords: immigration; Haiti; periphery; São Paulo; Global South.

\section{Introdução}

A imigração haitiana, até então pouco expressiva, se acentua no Brasil a partir dos anos 2010 e tem sido objeto crescente de estudos e pesquisas (Pimentel, Cotinguiba, 2014; Baeninger, 2016; Mamed, 2016; Silva, 2017; Baeninger, Peres, 2017; Magalhães, Bogús, Baeninger, 2018a, 2018b). O fenômeno se insere na discussão mais ampla sobre a reorganização da ordem internacional do trabalho

Mestranda em Ciências Humanas e Sociais, Universidade Federal do ABC. São Paulo, SP, Brasil. E-mail: erika.butikofer@ufabc.edu.br. Orcid: https://orcid.org/0000-0001-8321-6736.

** Pesquisadora de Pós-Doutorado em Ciências Humanas e Sociais na Universidade Federal do ABC. São Paulo, SP, Brasil. E-mail: elalves2014@gmail.com. Orcid: https://orcid.org/0000-00016925-8665. 
e a reformulação de trajetos migratórios, que em parte se deslocam do eixo Sul-Norte para o eixo Sul-Sul, isto é, entre países em desenvolvimento. Periféricos na periferia, para usarmos os termos de Villen (2015).

Esses fluxos migratórios em direção ao Brasil têm se conduzido especialmente para as grandes cidades, concentradoras de maiores oportunidades de trabalho (Magalhães, Bogús, Baeninger, 2018b) e, nesse contexto, São Paulo se apresenta atualmente como a cidade com maior concentração de imigrantes haitianos no país (Silva, Lima, Fernandes, 2018).

Este artigo discute as formas como imigrantes haitianos se estabelecem nas periferias da cidade, tomando o caso particular de Guaianases, distrito do extremo leste da capital paulista. Sabendo-se que as periferias de grandes cidades, como São Paulo, são marcadas historicamente como espaços de insuficiência de políticas públicas de várias ordens, como saneamento básico, saúde, moradia adequada, entre outras, quais são as experiências de acesso à cidade que encontramos no caso desses imigrantes? Como se constituem as redes de apoio de uma migração ainda recente, e quais mediações se colocam para que possam se estabelecer minimamente na cidade? Por fim, que caminhos se visualiza da passagem desses imigrantes da condição de trabalhadores (leitura econômica) para a de cidadãos de direitos (leitura sociopolítica), cujas demandas tenham visibilidade pública?

Para discutir tais questões esse artigo toma como objeto privilegiado as formas de acesso à moradia por parte desses sujeitos, consideradas na intersecção com a sua condição de trabalhadores de baixa remuneração. Moradia e trabalho são tomados como os eixos privilegiados de análise, entendidos como elementos fundamentais pelas quais imigrantes de baixa renda vão produzir suas condições de existência na cidade e a possibilidade de nela se estabelecerem definitivamente.

Nesse sentido, cumpre perguntar sob quais circunstâncias e mediações essas condições básicas são atendidas ou garantidas, entendendo-se que é a partir delas que se pode estabelecer, ou não, uma abertura mais ampla para o acesso à cidade e aos direitos. Vemos então ganhar relevância mediações de naturezas distintas, desde os expedientes informais de acesso habitacional até a importância da filiação religiosa, configurando experiências complexas de inclusão e direito à cidade que vão muito além da realização de condições materiais de existência.

A pesquisa, em curso desde 2017 no território em análise ${ }^{1}$, lançou mão do método etnográfico, com uso de técnicas de entrevista, gravadas e não gravadas. Foram realizadas entrevistas de trajetória, que possibilitam recuperar os percursos e deslocamentos realizados pelos entrevistados em relação a certos eixos previamente escolhidos pelo pesquisador (no caso, moradia, trabalho, imigração), permitindo articular histórias individuais e experiências coletivas (Telles, 2006). Assim, não se busca retratar a exemplaridade dos fenômenos discutidos mas

Essa pesquisa contou com financiamento da CAPES em parte de sua realização. 
recuperar, olhando "de perto e de dentro" (Magnani, 2002), as experiências dos sujeitos pesquisados e o que essas evidenciam de mediações privadas e públicas operantes no acesso à cidade.

O texto está dividido em 4 seções, além desta introdução e das considerações finais. Na primeira seção recuperamos a discussão sobre as migrações Sul-Sul e as condições de chegada de imigrantes haitianos no Brasil. Na segunda seção, tratamos da chegada e estabelecimento em São Paulo, das mediações operantes e experiências que levam os imigrantes a se instalarem na periferia da cidade. $\mathrm{Na}$ terceira seção, aprofundando o entendimento sobre as mediações, analisamos o papel da adesão religiosa no acesso à moradia. Na quarta seção discutimos quais possibilidades se colocam para que esse segmento social possa dar visibilidade pública a suas necessidades e privações, podendo abrir caminhos para o acesso à políticas públicas e a direitos.

\section{Do Haiti ao Brasil: trajetórias, mediações e experiências}

Estudos sobre o fenômeno da imigração têm sido uníssonos ao afirmar que a partir dos anos 2000 ocorre uma alteração importante na divisão internacional do trabalho e nas rotas migratórias tradicionais (Sassen, 2010; Baeninger, 2016). Em grande parte em função da crise econômica de 2007-2008, países de capitalismo avançado (convencionalmente chamados de Norte Global) acentuaram o rigor para a entrada de imigrantes, além de terem sofrido degradação nas condições de inserção econômica, produzindo alterações importantes nas rotas de imigração oriundas dos países do chamado Sul Global, e colocando países como o Brasil na rota de imigração de outras nações ditas periféricas, produzindo ou acentuando o fenômeno nomeado por Villen (2015) como "periféricos na periferia".

Diversos estudos sobre o fenômeno das migrações Sul-Sul, como o de Baeninger et al. (2018) e o Relatório Anual OBMigra (2019) apontam que o fluxo migratório para o Brasil, como país de trânsito ou de destino, foi composto nos últimos anos substancialmente por imigrantes do Sul Global, sendo a presença haitiana uma das mais expressivas (Fernandes, Milesi, Farias, 2015; Baeninger, 2015).

O crescimento da afluência de imigrantes haitianos ao Brasil costuma ser atribuído ao terremoto ocorrido naquele país em 2010. Porém, como lembra Magalhães (2018) é preciso considerar a multiplicidade de fatores que impulsionam ou caracterizam essa imigração e que passam por questões econômicas internas e a busca por oportunidades de trabalho fora; as transformações econômicas e políticas experimentadas pelos países desenvolvidos, rotas tradicionais dessa migração, como enfraquecimento das condições de trabalho e renda e aumento do rigor à entrada de imigrantes, sobretudo a partir da crise 2007-2008; e ainda fatores que atraem para o Brasil, como a presença do país no Haiti na Missão Minustah (desde 2004), a concessão de vistos humanitários (a partir de 2010) e a organização de grandes eventos como a Copa do Mundo (2014) e os Jogos 
Olímpicos (2016), acontecimentos que dependiam de uma grande massa de trabalhadores, principalmente da construção civil.

Quando falamos de imigração haitiana para o Brasil estamos tratando de uma imigração motivada, em sua maior parte, pela busca de trabalho ${ }^{2}$ e trata-se de uma inserção laboral no país que se faz nos circuitos mais precarizados e mal remunerados da economia, como a construção civil, os trabalhos domésticos, ou mesmo o comércio informal. Frequentemente, ao chegarem ao país os imigrantes sentem que as condições periféricas que deixaram pra trás se recolocam, pois "o trabalho aqui é pesado e vale pouco" (Villen, 2015, p. 259). Ademais, no caso da imigração haitiana, vemos operar ainda os fatores de preconceito e racismo, pois sabemos que a questão da racialização é uma noção fundamental para entendermos a inserção de imigrantes negros nas sociedades de acolhida (Pereira, 2020).

No contexto de uma crescente migração Sul-Sul e suas especificidades, esse artigo propõe explorar alguns elementos da experiência imigrante que vêm se desenhando para haitianos em São Paulo. Para isso seguiremos, como fio narrativo, elementos da trajetória de François, que por ter se tornado, ele próprio, figura de apoio para outros imigrantes, dá visibilidade às diferentes condições de vida dos conterrâneos, bem como às mediações que se constróem na busca de garantir-lhes condições mínimas de sobrevivência na cidade. Fazemos aqui, portanto, uma opção narrativa em que a exposição da trajetória e discursos desse entrevistado permite evidenciar e discutir diferentes situações e sujeitos observados na pesquisa de campo.

$* * *$

François $^{3}$ tem quarenta e seis anos, é natural de Marmelade (Mamlad, em crioulo). Em seu país era comerciante e também dedicou-se à profissão de professor e costureiro. Nasceu em meio a uma família cristã, mas decidiu ser pastor somente quando se estabeleceu no Brasil, país que, segundo ele, recebeu "todos os haitianos" depois do terremoto de 2010. Quando partiu para o Brasil, em 2012, tinha já dois filhos, e sua esposa estava grávida do terceiro. Porém, decidiu deixar o Haiti sozinho, com planos de trazer a família depois, uma vez estabelecido no país.

A viagem de François do Haiti até o Brasil durou três dias, passando por Panamá, Equador, Peru, até chegar em território brasileiro, pela cidade de Tabatinga (Amazonas), município localizado na tríplice fronteira entre Brasil, Colômbia e Peru. Tabatinga, como podemos ver na figura abaixo, faz parte de uma das mais importantes rotas da migração haitiana ao Brasil.

2 O que não significa desconsiderar os conteúdos históricos e culturais dessa imigração e a dimensão estruturante que a experiência diaspórica representa para o país, como argumentam Handerson (2015), Bersani (2016) dentre outros.

3 Em função da condição de irregularidade documental que marca muitos dos nossos entrevistados, optamos por utilizar sempre o nome fictício, mesmo quando não seja esse o caso. Vale destacar que as entrevistas seguiram os procedimentos éticos exigidos, como a assinatura do Termo de Consentimento Livre e Esclarecido. 
Figura 1 - O caminho dos haitianos

O caminho dos haitianos

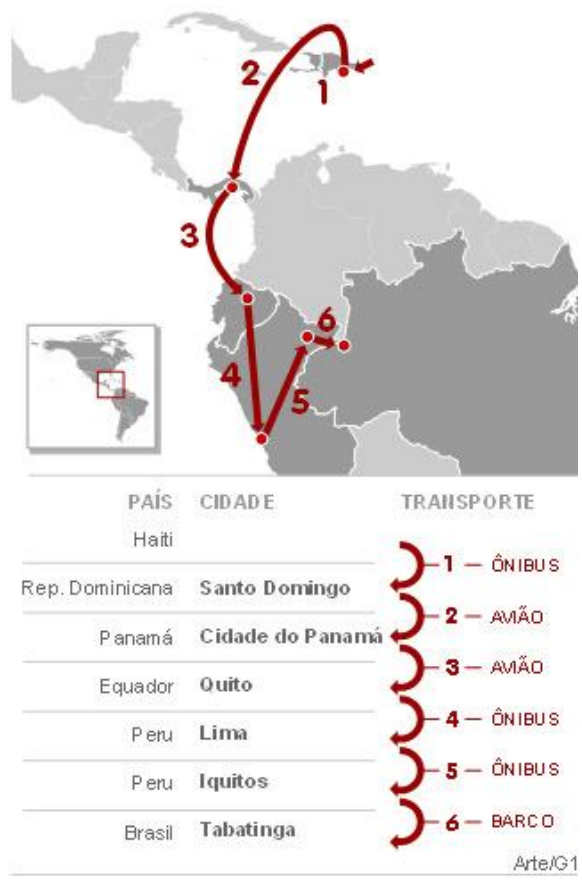

Fonte: Haitianos viajam de avião, ônibus e barco por emprego na Amazônia. G1 Brasil (14.02.11). Acesso em: 29.03.2020.

François relata as difíceis condições de chegada ao país, iniciadas já na demora e dificuldade para obtenção de documentos, que pode levar semanas e até meses, como mostra a pesquisa de Fernandes e Faria (2017).

Diante da insuficiente e precária recepção dos imigrantes na entrada ao Brasil, desde cedo são formadas redes de solidariedade e apoio entre os próprios imigrantes, que vão desde o compartilhamento de hospedagem por parte daqueles que chegam com algum recurso para pagar por ela, até a acolhida em abrigos improvisados e de cunho humanitário, principalmente organizados pela igreja Católica (Silva, 2017). O próprio François acolheu três imigrantes na casa que alugou emergencialmente e expôs com tristeza as condições de precariedade em que encontrou seus conterrâneos chegando ao Brasil: "é ruim sair da minha terra por conta da miséria e vejo como as pessoas estão, vejo miséria de novo".

Essa descrição preliminar da experiência narrada por François faz eco àquelas relatadas por diferentes pesquisas voltadas ao assunto (Pimentel, Cotinguiba, 2014; Silva, 2017; Fernandes, Faria, 2017). Nota-se como alianças e laços de solidariedade, coordenados pelos próprios imigrantes, oferecem alguma 
organização e suporte para a situação que desde o momento de chegada é vivida com privações, quando não violação de direitos. Seguindo a trajetória de François vemos como tais arranjos são igualmente presentes (e necessários) quando da chegada à cidade de destino final, no caso, São Paulo.

\section{São Paulo como destino: periferia, trabalho e moradia na trajetória migrante}

O primo de François já estava estabelecido em Guaianases quando ele chegou a São Paulo, na madrugada de cinco de fevereiro de 2012, um mês depois de ter deixado o Haiti. Perfazendo um percurso comum a muitos imigrantes que chegam a São Paulo com poucos recursos e sem conhecimento do idioma local, sua trajetória ocupacional se dá nos serviços de baixa qualificação, no seu caso a construção civil e os serviços de limpeza. Na construção civil entrou logo quando da chegada à cidade, por indicação do primo, na empresa em que esse trabalhava. A atividade, pesada e de baixa remuneração, o faz avaliar a trajetória como um descenso profissional em relação a sua trajetória ocupacional no Haiti:

O trabalho na minha terra era muito sossegado (...) mas quando cheguei no Brasil, o pessoal me pediu para trabalhar na construção civil porque não falava nada (de português). Fazia massa, carregava massa. É pesado, é ruim. Estava chorando muito. Um dia o encarregado me chamou para descarregar cimento (...). Depois de descarregar cimento fui no cantinho sentar e só chorar lembrando da minha terra porque (lá) estava muito bem e saí para trocar de vida e (aqui) foi bem mais feio. ${ }^{4}$

Muitos dos nossos interlocutores estão inseridos em condições semelhantes de trabalho, quase sempre nos serviços de baixa qualificação ${ }^{5}$, seja em empresas, restaurantes, supermercados, na construção civil, ou oficinas de costura, onde desempenham funções como ajudantes gerais e de limpeza, repositores de mercadorias, embaladores, serventes de obras, pedreiros, costureiros, entre outras. O acesso a uma vaga de trabalho passa, em geral, pela indicação de algum familiar ou amigo já empregado no local, evidenciando a importância das redes de solidariedade na instalação desses imigrantes na cidade.

Quando fora dos circuitos formais da economia ${ }^{6}$, o comércio ambulante se configura como fonte de renda para muitos deles, atividade que realizam por conta própria e onde contam com diversos auxílios para a compra inicial das mercadorias. O comércio é feito especialmente na região central do distrito, nas proximidades da estação de trem de Guaianases, e mais frequentemente na região central

4 Entrevista concedida às autoras em 20 de fev. de 2020.

5 Segundo Relatório Anual OBMigra isso se deve, em grande parte, por terem, em sua maioria, um nível de instrução abaixo do que seria nosso ensino médio (Cavalcanti, Oliveira, Macedo, 2019). Entretanto, mesmo aqueles que têm uma maior qualificação não têm acesso a trabalhos melhor remunerados, pois a admissão a cargos superiores passa por fatores objetivos como validação de diplomas ou subjetivos como em situações de racismo e de xenofobia (Pereira, 2020).

6 Os imigrantes de nacionalidade haitiana são os que mais estão inseridos no mercado de trabalho formal (Cavalcanti, Oliveira, Macedo, 2019). 
da cidade. Sobretudo neste último caso estão sempre sujeitos às operações de fiscalização municipais, tendo correntemente seus bens confiscados, obrigando-os a recomeçar as atividades do zero, o que exige, muitas vezes, endividamento.

Nesse sentido, seja pelos baixos salários, seja pela própria instabilidade e insegurança em relação aos rendimentos, esses trabalhadores imigrantes vêem conformar-se em São Paulo uma trajetória profissional atravessada por privações, o que se desdobra igualmente em outras dimensões da vida na cidade, como o acesso à saúde ou à moradia.

Pelos registros da Polícia Federal, o estado de São Paulo reúne a maior concentração de imigrantes haitianos, ganeses, congoleses, entre outros (Silva, Lima, Fernandes, 2018). A maioria deles acaba residindo em territórios onde já há vínculos familiares e de amizade, o que facilita o seu estabelecimento. Na capital paulista, que pelo seu dinamismo econômico atrai muitos imigrantes, o distrito de Guaianases se destaca como importante polo de atração na periferia da cidade. Para lá se dirigiram dois significativos fluxos migratórios recentemente: o da comunidade nigeriana, a partir de 2009, e o de haitianos, mais expressivamente a partir de 2014 (Imigrantes..., 2015).

Certamente ainda há muito o que investigar sobre os impactos intra-urbanos da recomposição dos circuitos migratórios no contexto Sul-Sul e a atração exercida por certas regiões da cidade por parte de determinados grupos. De todo modo, é preciso situar Guaianases como um bairro que historicamente se constituiu como espaço de moradia para populações de baixa renda, que vinham se empregar na industrialização nascente, notadamente a partir das décadas de 1930 e 1940 . O processo de desindustrialização por que passou a cidade e a Região Metropolitana de São Paulo alterou substantivamente os circuitos econômicos nos quais essa região se insere (Silva, 2008), mas sem alterar sua condição de "cidade-dormitório" para as populações pobres, que trabalham em outras regiões da cidade.

Como já muito relatado nos estudos urbanos, a expansão dessas regiões periféricas se deu por meio dos loteamentos clandestinos e a autoconstrução da casa própria (Bonduki, 2002). A histórica insuficiência de políticas habitacionais e urbanas fizeram com que as periferias da cidade se expandissem em condições precárias e de ausência de serviços e infra-estrutura, constituindo-se em alternativa mais barata e acessível para os trabalhadores de baixa renda.

Em parte, é nesse contexto territorial que se instalam hoje os imigrantes de países periféricos. É preciso lembrar que parte dessas regiões da cidade já passou por processos de consolidação importantes, em termos de serviços e equipamentos públicos, o que faz com que em muitas áreas os aluguéis sejam elevados. Restam, pois, para os imigrantes que chegam com poucos recursos à cidade, as áreas mais precárias, casas e cômodos de aluguel em péssimas condições estruturais de construção, contratos informais, e que muitas vezes podem ter seus valores elevados em função da demanda crescente. Para esses imigrantes, distritos 
periféricos como Guaianases disponibilizam um mercado informal de aluguéis mais acessíveis, e acesso menos burocratizado no momento de locação, sem os adiantamentos financeiros ou os parâmetros de renda que seriam exigidos em bairros da chamada cidade formal.

François chegou em Guaianases em situação relativamente melhor que a de grande parte de seus conterrâneos, por contar com alguma reserva material trazida do Haiti, e podendo contar com o primo para lhe indicar trabalho e casa para locação. Assim, quase imediatamente empregado, cedo conseguiu alugar uma casa, dependendo por pouco tempo do abrigo oferecido pelo familiar. Como é comum entre imigrantes, nota-se operar em sua trajetória a "família-rede", que contribui para orientar certos fluxos em direção a determinados bairros da cidade. Vemos operar uma espécie de cadeia migratória que pode ser definida "como o deslocamento de indivíduos motivados por uma série de arranjos e informações fornecidas por parentes e conterrâneos já instalados no local de destino" (Truzzi, 2008, p. 200).

Note-se que a porta de entrada para muitos imigrantes que chegam a São Paulo sem poder contar de imediato com família ou amigos são os abrigos oferecidos pela prefeitura municipal. Com exceção do Centro Temporário de Acolhimento de São Mateus, que acolhe venezuelanos desde abril de 2018, todos os outros credenciados pela prefeitura - Centro de Acolhida Especial para Mulheres Imigrantes (CAEMI Penha) e os Centros de Referência e Atendimento para Imigrantes (CRAI) Pari e Bela Vista - têm vinculação com organizações da igreja católica. Porém, pela insuficiência de leitos, muitos dos que permanecem no centro da cidade acabam por abrigarem-se ora em outras instituições de acolhida, ora em igrejas migrantes ${ }^{7}$ de diferentes denominações que servem de moradia improvisada. Ou ficam sujeitos a períodos de desabrigo, engrossando por vezes a população em situação de rua que vive na região.

Aqueles que conseguem sair dessa situação de moradia temporária, dados os altos custos de se morar no centro da cidade, dirigem-se frequentemente a bairros periféricos, onde Guaianases tem ganhado grande destaque ${ }^{8}$.

As condições de acesso à moradia na periferia de São Paulo são atravessadas por múltiplos obstáculos, já presentes na vida dos nacionais, mas que ganham novos contornos na experiência dos imigrantes, mobilizando outras mediações e evidenciando diversas vulnerabilidades. Ao mesmo tempo, realizam-se aí os agenciamentos que permitem fazer frente às dificuldades encontradas, seja na forma de uma possível organização coletiva, seja nas redes de solidariedade que se fazem nas fronteiras entre o formal e o informal na busca por construir condições razoáveis de vida na cidade.

\footnotetext{
Tendo como exemplo a igreja nigeriana Christian Community of Ministry International (CCMI) localizada na Avenida Rio Branco, região central da cidade.

8 Como também os bairros de Artur Alvim, Itaquera e Penha (Haydu, 2017).
} 
Desde que chegou a São Paulo, François precisou mudar de casa sucessivas vezes. Frágeis condições estruturais dos imóveis alugados, como alta umidade ou áreas sujeitas a alagamento, o fizeram mudar ao menos duas vezes, numa delas tendo perdido a totalidade dos móveis por conta de uma enchente. Em outra situação, decidiu deixar a casa em função da presença de tráfico e uso de drogas nas imediações, o que o fazia temer pela segurança dos filhos.

As razões que motivam os deslocamentos habitacionais de François evidenciam elementos importantes no acesso à cidade e à moradia por parte desses imigrantes moradores de periferias urbanas: um mercado locacional informal e precário, que responde por necessidades habitacionais na ausência de políticas e insuficiência de recursos próprios; bairros vulneráveis sujeitos às intempéries naturais e à violência urbana; e, por fim, o papel fundamental das redes familiares e de apoio como suporte necessário (ou mesmo, imprescindível) ao estabelecimento na cidade.

Nossa pesquisa mostra muitos desses imigrantes morando em pequenos cômodos sublocados em sobrados ou casas contíguas em um mesmo lote, frequentemente divididos com outros imigrantes, comumente da mesma nacionalidade. Mesmo os estabelecidos há mais tempo vivem com a preocupação de manterem meios de sobrevivência e renda para poderem pagar seus aluguéis, sob o risco de sofrerem despejos, sem que a condição informal de muitos deles permita ter acesso à justiça e demais mecanismos de proteção dos direitos.

Nesse contexto de difíceis condições de acesso habitacional, vemos ganhar relevância em São Paulo a presença de imigrantes junto a movimentos organizados de moradia. Silvia Zelaya (2016), em seu trabalho sobre o acesso e a liderança de imigrantes em movimentos de luta por moradia no centro, argumenta sobre a possibilidade e apelo da auto-organização dessa população em movimentos desse tipo, deslocando-os "tanto da imagem do refugiado enquanto 'vítima' como daquela do imigrante enquanto 'força de trabalho'“ (Zelaya, 2016, p. 402) .

Estabelecidos na periferia da cidade, diante das difíceis condições de acesso à moradia, também os imigrantes ficam sujeitos à ação de grileiros e à venda ilegal de lotes, fenômeno de longa data nessas regiões periféricas mas que, nesse caso, certamente merece maiores esforços investigativos, a fim de que se conheçam as possíveis particularidades em jogo. Na sua atuação recente com a comunidade imigrante, François relata esse tipo de situação, ao mencionar um processo de reintegração de posse ocorrido em 2018, e que deixou os moradores (muitos deles imigrantes) desabrigados:

\footnotetext{
9 Em 2014, diversos imigrantes e refugiados de diferentes países uniram-se para fundar o Grupo de Refugiados e Imigrantes Sem-Teto (GRIST). Esta organização da sociedade civil se aproximou de movimentos sociais brasileiros já consolidados, como o Movimento dos Sem Teto no Centro (MSTC) e a Frente de Luta por Moradia (FLM), evidenciando que a luta por moradia digna é também uma questão da comunidade imigrante.
} 
O povo brasileiro pegou todo o terreno e vendeu para o haitiano, vendeu para o africano também, vendeu para o boliviano. Chegou em um momento que o dono do terreno pediu para a prefeitura tirar todo mundo. A prefeitura (sic) chamou eu para conversar sobre isso. Quando chamaram eu, eles mentiram para mim, prometeram muito, e nunca resolveram até hoje. (...) desde aquele momento tiraram eles, deixaram na rua. Limpou o terreno. (...) até uma cesta básica não deram para ninguém ${ }^{10}$.

Foto 1 - Campinho da favela Rendzina, Lajeado. Local onde muitos brasileiros e imigrantes de diversas nacionalidades se encontram para jogar futebol

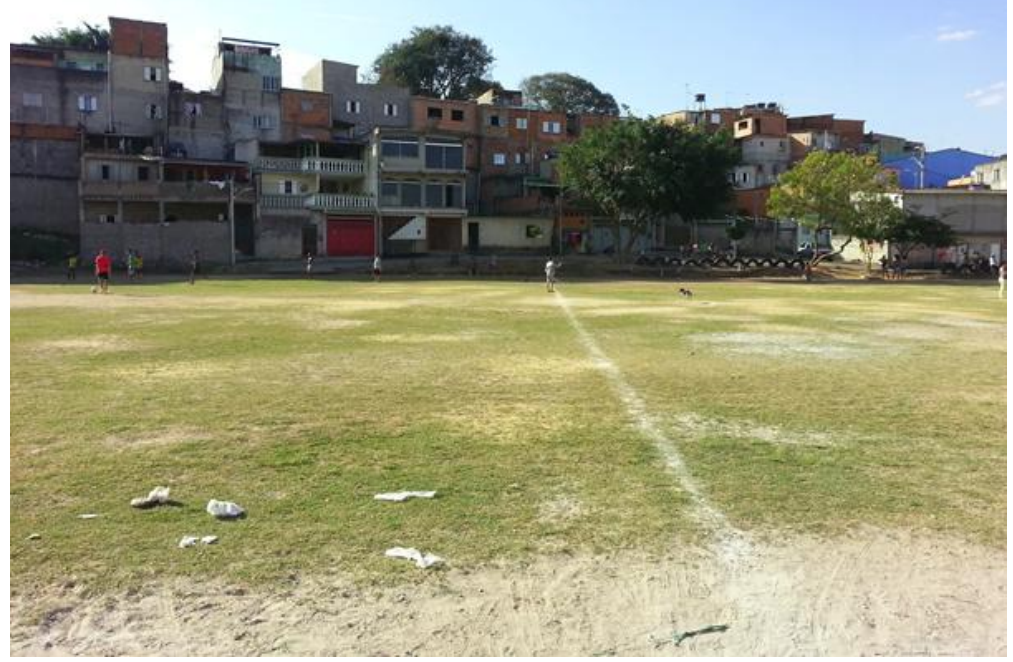

Fonte: Foto tirada em julho de 2016. Arquivo pessoal (2016).

Nesse processo de reintegração de posse François foi um dos importantes interlocutores procurados pelos imigrantes, na expectativa de mediação junto à administração local (subprefeitura), em função do lugar que passou a ocupar desde que se tornou pastor da igreja batista.

Todos os nossos interlocutores, em algum momento de suas trajetórias, afirmam ter acolhido parentes, amigos ou conterrâneos em suas casas. Na realidade, essa acolhida faz parte de uma rede de solidariedade e apoio que se fundamenta não só no âmbito familiar, mas também em suas adesões religiosas. É sobre esse ponto que nos deteremos na seção seguinte.

\footnotetext{
${ }^{10}$ Entrevista concedida às autoras em 20 de fev. de 2020.
} 


\section{O papel da adesão religiosa na organização de moradia de migrantes haitianos em Guaianases}

Na narrativa de François, o seu primo foi o "primeiro" haitiano a residir em Guaianases, chegando ao bairro em agosto de 2011; ele teria sido o "segundo", instalando-se em fevereiro de 2012. Sua percepção de 'pioneiro' traduz, em termos metafóricos, o caráter recente da migração haitiana naquele distrito.

No período inicial de vivência no bairro, François tratou de conhecer "todas" as igrejas protestantes do território, em parte pela sua própria confissão religiosa, em parte como mapeamento de redes de apoio e solidariedade. Visitou igrejas adventistas, batistas e assembléias de Deus. A partir de uma demanda advinda da comunidade brasileira da igreja batista de Guaianases começou a desenvolver um papel importante de mediação entre haitianos e brasileiros, já que estes encontravam dificuldades para comunicarem-se com a população haitiana que vinha em busca de seu apoio e assistência. As pessoas ligadas à igreja queriam alguém da comunidade imigrante para ajudá-las na distribuição de cestas básicas e outras doações.

A partir de 2013, quando iniciou sua atuação como mediador entre a comunidade haitiana e a igreja batista, François começou a ficar conhecido pela população haitiana do bairro. Apoiado pelo pastor da igreja à qual se filia, em agosto de 2013 ele criou sua própria comunidade: a igreja batista haitiana de Guaianases, que virá a se constituir como uma importante referência para os que chegam, não só pelo acolhimento religioso ofertado, mas pela ampla rede de apoios e arranjos que mobiliza para viabilizar a inserção dos imigrantes na cidade, constituindo-se, assim, mais um elemento para a orientação de fluxos migratórios e de fixação dos recém-chegados naquele bairro.

Quem passa a frequentar a igreja batista haitiana precisa, inicialmente, fazer um cadastro. Desse modo, a comunidade consegue saber sobre a situação migratória dos recém-chegados na cidade: entre outras coisas, se possuem dinheiro para alugar uma casa, se têm algum familiar já estabelecido no bairro ou se teriam oportunidades de trabalho de imediato.

A igreja passa, pois, a operar como uma mediação importante corroborando uma rede de sociabilidades e apoios materiais e simbólicos nos vários aspectos da vida dos recém-chegados (ou mesmo para aqueles que a procuram mais tarde, em condições de necessidade), em termos de facilitar o acesso às condições básicas para sua instalação no local: trabalho, moradia, indicação de serviços públicos ou organizações de apoio para atividades como o aprendizado do português, doações, dentre outros. São redes e apoios que nos permitem pensar a condição dos imigrantes para além do registro da falta ou ausência, recuperando os recursos que os mesmos mobilizam ou criam ao se estabelecerem nos locais de destino. Conforme descreve Handerson (2015, p. 66), “a pessoa diáspora possui diversos recursos culturais adquiridos em diferentes espaços de mobilidade e de 
pertencimento, o que lhe permite criar outros espaços de referência", como as suas próprias igrejas, no caso em análise.

Em função das diferentes necessidades há uma organização interna da igreja em "comitês" dedicados a cada assunto específico. A partir daí se formam redes com a comunidade externa, brasileiros ou imigrantes instalados há mais tempo, capazes de garantir o acesso a doações, indicações de vagas de trabalho, contratos de locação etc.

Nessa organização promovida pela igreja, quem chega e se instala no bairro muitas vezes passa a fazer parte da rede, especialmente com indicações de local de trabalho e moradia. Isso faz com que as redes se ampliem, ainda que seja grande o número de flutuantes, ou frequentadores ocasionais. Por meio dessas práticas se constituem redes de apoio até mesmo para quem ainda está por vir, como comenta François à propósito das estratégias para o aluguel de casas:

(...) se tem outro haitiano que mora em uma casa grande dá para 'segurar' um pessoal até achar um serviço (...) Às vezes quando a gente aluga uma casa para uma pessoa, falamos para o proprietário que vão morar duas pessoas, porque quando chegar alguém ela não pode ficar na rua. ${ }^{11}$

Importante notar como esse gerenciamento de acesso à moradia, se tem por função atender à necessidade material da instalação dos imigrantes na cidade, não deixa de ser atravessado pelos códigos morais e simbólicos da denominação religiosa. Assim, a própria comunidade se organiza em comitês subdivididos por gênero e estado civil, responsáveis pelos diferentes públicos. Tratando-se de um imigrante do sexo masculino, solteiro ou casado, pode ser alocado na casa de outro imigrante do mesmo sexo. Se for uma mulher solteira, ficará alojada em um local onde morem outras mulheres. Se vier uma família, o comitê procura uma casa/cômodo separada para eles.

Assim, dificilmente se verá arranjos onde jovens de diferentes sexos, por exemplo, possam morar sob o mesmo teto. Isto porque os arranjos feitos para consecução de uma casa são atravessados pelos códigos morais da própria igreja:

Criamos um comitê no WhatsApp para arranjar moradia para as pessoas que estão chegando em Guaianases. Mulher casada tem um conselho, homem casado também tem um conselho, jovens têm outro. Por exemplo, se você tem dinheiro, passa no grupo, quem achou a casa encaminha para a pessoa. Existem comitês de homens e mulheres. Ajudam nas cestas básicas também, arrecadam dinheiro para os que mais precisam. ${ }^{12}$

A partir dos relatos notamos que a igreja é um espaço que tem uma dimensão social híbrida e estendida, que combina o apoio material (moradia, trabalho, doações) ao suporte simbólico e de recomposição do sentimento de pertença, acolhida e reciprocidade dos imigrantes.

\footnotetext{
${ }^{11}$ Entrevista concedida às autoras em 20 de fev. de 2020.

${ }^{12}$ Entrevista concedida às autoras em 20 de fev. de 2020.
} 
A rede de solidariedade, que em um primeiro momento solidifica-se nos laços familiares, agora é acrescida da adesão religiosa, muito significativa para a (re)construção da vida dessa população no país estrangeiro. A observação dessas redes sociais da migração nos propicia uma concepção mais ampla da composição social, cultural, simbólica e territorial dos fluxos migratórios, que incluem vínculos familiares, de amizade, de origem e de filiação religiosa.

\section{Foto 2 - Apresentação do grupo das mulheres casadas no aniversário de 6 anos da igreja batista haitiana de Guaianases}

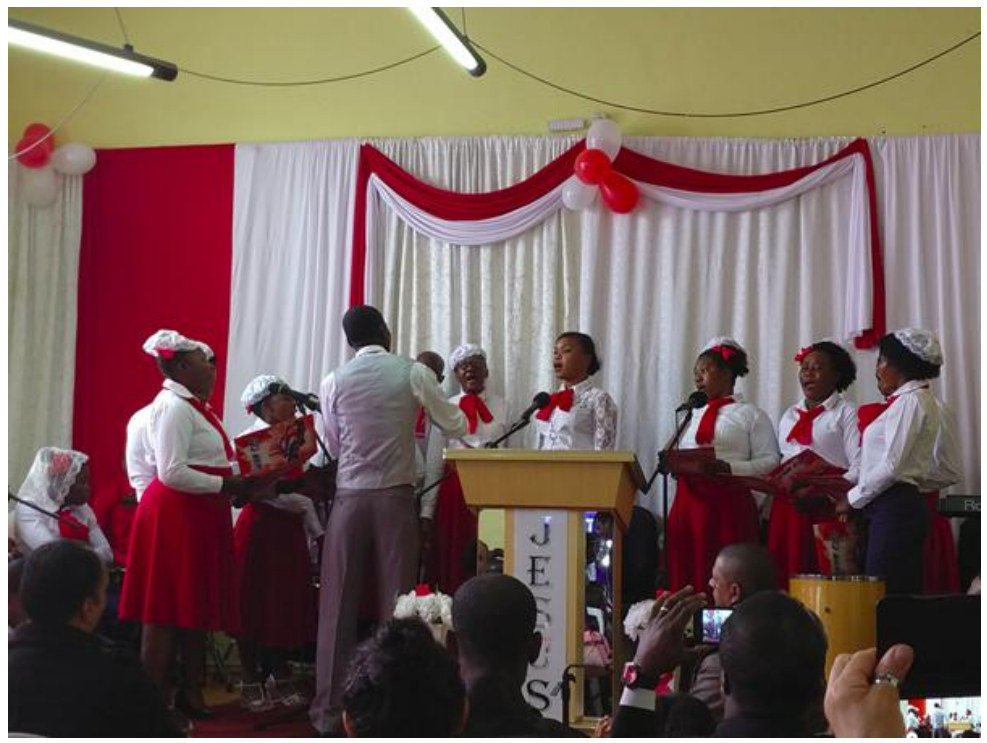

Foto tirada em agosto de 2019. Fonte: Arquivo pessoal (2019).

Por outro lado, na busca de apoios e suportes, os fiéis também podem transitar por coletividades distintas, capazes de responder às necessidades de certo momento. Assim, em alguma medida, poderíamos dizer que "a afiliação religiosa seria ela própria a variável dependente, subordinada à decisão de associar-se a uma rede social com o objetivo de usufruir de seus possíveis benefícios" (Martes, Rodriguez, 2004, p. 123).

Assim, compreendemos porque vimos muitos adeptos da comunidade haitiana (e de outras nacionalidades) circularem entre igrejas evangélicas de várias denominações à procura de cestas básicas, doações, como também de auxílio financeiro para quitarem dívidas. Arranjos que muitas vezes, avalia François, provocam vergonha ou constrangimento para aqueles que não conseguem "retribuir" - em uma lógica de dádiva entre dar-receber-retribuir (Mauss, 1974) - a ação solidária que receberam da coletividade, buscando igrejas vizinhas em busca de novas medidas de assistência e proteção. 


\section{Migração, demanda coletiva e visibilidade pública}

Em 2014, o Conselho Participativo Municipal de São Paulo estendeu esse espaço à participação de imigrantes, para que pudessem se candidatar como conselheiros $^{13}$, sendo a capital paulista, atualmente, a única do país a dispor desse tipo de iniciativa política ${ }^{14}$. Desde então, o Conselho Municipal de Imigrantes (CMI), regulamentado pelo Decreto Municipal 57.533/2016, tornou-se um espaço de ação política relevante para esse grupo social e para a própria dinâmica da cidade. Exemplo disso é a consolidação do Centro Educacional Unificado (CEU) Jambeiro como uma de suas zonas eleitorais, devido à numerosa população imigrante moradora da região de Guaianases.

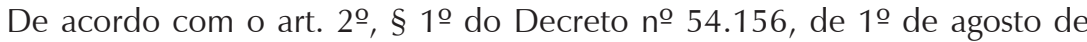
2013 (SÃO PAULO, 2013) "O Conselho Participativo Municipal é um organismo autônomo da sociedade civil, reconhecido pelo Poder Público Municipal como instância de representação da população de cada região da Cidade", e tem como atribuições oferecer aos cidadãos o direito ao controle social, à fiscalização de ações e gastos públicos, como também viabilizar as prioridades e demandas de cada região da cidade.

Por conta da importância ganha por François como interlocutor de imigrantes de diferentes nacionalidades e igrejas (brasileiras, haitianas, africanas), em dezembro de 2019 candidatou-se para representá-los no conselho participativo do distrito de Lajeado, subprefeitura de Guaianases, onde tomou posse em fevereiro de 2020, para um mandato de dois anos.

Como representante eleito, François foi chamado para apontar as principais demandas dos imigrantes, para que pudessem ser pautadas e enfrentadas nas ações do conselho. Passo importante em um contexto em que a realidade imigrante ainda é pouco ouvida pela gestão local, como ele lembra: "O 'governador' (sic) nunca conversou com nós para saber como funciona a igreja".

A eleição de François ao conselho participativo abre a possibilidade de uma elaboração coletiva das demandas imigrantes que se estabelecem em bairros periféricos, não apenas para haitianos, como ele apresenta:

Primeiro, tem que ter um lugar para receber os imigrantes. Segundo, os imigrantes sofrem muito em Guaianases, não só em Guaianases, em São Paulo inteira. Porque no hospital os imigrantes que não sabem falar a língua... Precisam de um tradutor. Tem que ter um lugar que atenda os imigrantes em Guaianases.

${ }^{13}$ Registramos nossa homenagem à conselheira Oriana Jara Maculet falecida em dezembro de 2020. Imigrante chilena, fundadora da organização Presença da América Latina (PAL), foi uma importante militante e ativista das causas migratórias dentro e fora das esferas públicas municipais, sua trajetória será por nós sempre lembrada pela sua incansável luta pelos direitos dos imigrantes no Brasil.

${ }^{14}$ O Conselho Municipal de Imigrantes (CMI) de São Paulo é um órgão colegiado paritário e vinculado à Coordenação de Políticas para Imigrantes e Promoção do Trabalho Decente (CPMigTD), da Secretaria Municipal de Direitos Humanos e Cidadania (SMDHC). 
Os haitianos estão espalhados por vários bairros de Guaianases. Têm africanos também. Todos misturados ${ }^{15}$.

O depoimento de François vai ao encontro das reivindicações por atendimentos humanizados e capacitação de profissionais de serviços públicos das áreas da saúde, da educação, da assistência social, entre outras, constatadas, desde 2013, na 1o Conferência Municipal de Políticas para Imigrantes. Algumas delas vêm sendo implementadas, como a criação de unidade móvel do Centro de Referência e Atendimento para Imigrantes (CRAI), em 2019, que conta em seus quadros com imigrantes bilíngues e/ou poliglotas. Mas ainda se faz necessária a admissão de imigrantes nas equipes dos demais serviços públicos que recebem essa população, garantindo-lhes assim um atendimento que considere a sua diversidade linguística e cultural.

Adicionalmente, a questão da promoção do acesso à moradia, da flexibilização e desburocratização do processo de aluguel, são algumas das pautas discutidas no âmbito do $\mathrm{CMI}^{16}$.

As demandas relatadas por François mostram o elevado nível de vulnerabilidade em que vivem esses grupos ao chegarem à cidade. Experiência presente desde a chegada ao país e que se recoloca na cidade de destino final, vivendo em casas insalubres e precárias, sofrendo com a inadequação de atendimento nos serviços de saúde, pelo desconhecimento da língua portuguesa.

Assim, a criação de um órgão colegiado na cidade mais populosa da América do Sul, é uma importante ferramenta política para a construção de um diálogo permanente entre sociedade civil e poder público. E isso se deve à reivindicação pelo protagonismo imigrante, que conta com a participação cada vez maior de organizações, associações, movimentos sociais e coletivos próprios na promoção de sua autonomia, na garantia de divulgação e monitoramento de acesso a direitos e no combate ao racismo, à xenofobia e outras formas de violência e discriminação.

Que os conselhos participativos possam dar a conhecer essas demandas, e que estas possam ser tratadas pela gestão local e as políticas públicas, é certamente caminho necessário para lidar com essas novas dinâmicas presentes na periferia paulistana: há décadas espaços de acolhimento das classes trabalhadoras vindas de diferentes regiões do país e, mais recentemente, reconfigurada também pela presença desses trabalhadores imigrantes, em sua maioria negros, vindos de países do Sul Global como da América Latina, Caribe e África.

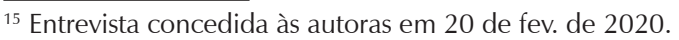

${ }^{16}$ Para saber mais, veja o relatório final da $2^{\circ}$ Conferência Municipal de Políticas para Imigrantes - Somos todos cidadãos. Disponivel em: < https:/www.prefeitura.sp.gov.br/cidade/secretarias/ upload/direitos_humanos/participacao_social/CONSELHOS/CONSELHO\%20IMIGRANTES/ CONFERENCIA/Versao\%20Links.pdf>. Acesso em: 04.02.2021.
} 


\section{Considerações finais}

As migrações Sul-Sul acrescentam problemáticas novas àquelas dos estudos tradicionais das imigrações no sentido Norte. Em casos de imigração recente, como é o caso da presença haitiana no Brasil, resta ainda muito a conhecer sobre seus efeitos sociais, políticos ou econômicos.

Ao chegarem em um país também periférico esses imigrantes encontram condições próprias em relação àquelas encontradas nos destinos tradicionais de países desenvolvidos (não raro romantizadas por eles quando se defrontam com as agruras brasileiras), dividindo com a população local os postos de trabalho e as condições precárias de moradia. Se a semelhança de condições pode gerar, por vezes, aproximações e relações amistosas entre nacionais e estrangeiros (expressas, por exemplo, nos jogos de futebol nos campos de várzea, com times mistos, no namoro entre os jovens), não está livre das expressões de preconceito e racismo, especialmente em espaços de disputa econômica, como é o mercado de trabalho (Villen, 2015).

Embora o Brasil tenha aberto a possibilidade dos vistos humanitários e, de algum modo, incentivado a imigração haitiana desde os anos 2010, na prática as mediações públicas têm sido claramente insuficientes para dar conta de boas condições de acolhida e estabelecimento no país. Diante disso, são sobretudo as redes de apoio, familiar ou de adesão religiosa, aquelas que conseguem, de alguma forma, garantir suporte mínimo para o estabelecimento desses imigrantes na cidade. Mas note-se que estamos falando de um lugar de agência desses sujeitos, em que as diferentes mediações (formais ou informais) podem ser acionadas e combinadas em função dos seus próprios recursos materiais ou simbólicos.

A organização coletiva, como aquela da luta política dos movimentos sociais, parece ser ainda incipiente entre esses imigrantes, situação em que a criação do GRIST é um importante exemplo, mas cuja extensão e características ainda precisam ser melhor compreendidas, bem como a possibilidade efetiva de fazerem a passagem da solidariedade aos direitos.

A abertura do Conselho Participativo da cidade de São Paulo à participação dos imigrantes representa, certamente, um avanço importante não só para a visibilidade política das demandas desses grupos, mas ainda seu reconhecimento como cidadãos com direito à voz em instâncias públicas. Possibilidade política de passagem da condição de trabalhador, que impele sua partida do país de origem, à condição de sujeito de direitos no país destino. Mas também possibilidade sociológica do país qualificar a cordialidade que se auto-atribui. Conceito que se banalizou na (falsa) imagem do afeto e identidade com o outro que é "trazido para perto", mas que lhe nega reconhecimento e valoração social. 


\section{Referências bibliográficas}

BAENINGER, Rosana. Migrações contemporâneas no Brasil: desafios para as políticas sociais. In: PRADO, Erlan José Peixoto do; COELHO, Renata (orgs.). Migrações e trabalho. Brasília: Ministério Público do Trabalho, 2015, p. 79-86.

BAENINGER, Rosana et al. (org.). Imigração Haitiana no Brasil. Jundiaí: Paco Editorial, 2016.

BAENINGER, Rosana; PERES, Roberta. Migração de crise: a migração haitiana para o Brasil. Revista Brasileira de Estudos de População, v. 34, n. 1, 2017, p. 119-144.

BAENINGER, Rosana et al. (orgs.). Migrações Sul-Sul. Campinas: Núcleo de Estudos de População "Elza Berquó" - Nepo/Unicamp, 2018.

BERSANI, Ana Elisa. Chache lavi Deyò: uma reflexão sobre a categoria refúgio a partir da diáspora haitiana no Brasil. Cadernos de Campo, São Paulo, n. 25, p. 383-399, 2016.

BONDUKI, Nabil. Origens da habitação social no Brasil: Arquitetura moderna, lei do inquilinato e difusão da casa própria. São Paulo: Estação Liberdade/Fapesp, 2002.

CAVALCANTI, Leonardo; OLIVEIRA, Tadeu de; MACEDO, Marília de (orgs.). Imigração e Refúgio no Brasil. Relatório Anual 2019. Série Migrações. Observatório das Migrações Internacionais; Ministério da Justiça e Segurança Pública/ Conselho Nacional de Imigração e Coordenação Geral de Imigração Laboral. Brasília, DF: OBMigra, 2019. Disponível em: <https://portaldeimigracao.mj.gov.br/images/ relatorio-anual/RELAT\%C3\%93RIO\%20ANUAL\%20OBMigra\%202019.pdf>. Acesso em: 14.02.2021.

FERNANDES, Durval; MILESI, Rosita; FARIAS, Andressa. Do Haiti para o Brasil: o novo fluxo migratório. Brasília: IMDH, 2015.

FERNANDES, Duval; FARIA, Andressa Virgínia de. O visto humanitário como resposta ao pedido de refúgio dos haitianos. Revista Brasileira de Estudos de População, v. 34, n. 1, p. 145-161, jan./abr. 2017.

Haitianos viajam de avião, ônibus e barco por emprego na Amazônia. Portal G1, 14.02.2011. Disponível em: < http://g1.globo.com/brasil/noticia/2011/02/haitianos-viajamde-aviao-onibus-e-barco-por-emprego-na-amazonia.html> . Acesso em: 14.02.2021.

HAYDU, Marcelo. Refugiados congoleses na cidade de São Paulo: processo migratório e itinerários terapêuticos. Tese de Doutorado. Universidade Federal de São Paulo, São Paulo, 2017.

Imigrantes mudam rotina e paisagem de Guaianases. Folha de São Paulo, São Paulo, 20.09.2015. Disponível em: <http://feeds.folha.uol.com.br/fsp/cotidiano/233658imigrantes-mudam-rotina-e-paisagem-de-guaianases.shtml>. Acesso em: 14.02.2021.

JOSEPH, Handerson. Diáspora. Sentidos Sociais e Mobilidades Haitianas. Horizontes Antropológicos, n. 43, p. 51-78, jan./jun. 2015.

MAGALHÃES, Luís Felipe Aires. Migração de dependência: considerações teóricas e metodológicas sobre a imigração haitiana no Brasil". In: BAENINGER, Rosana et al. (orgs.). Migrações Sul-Sul. Campinas: Núcleo de Estudos de População "Elza Berquó" - Nepo/Unicamp, 2018, p. 383-401. 
MAGALHÃES, Luís Felipe Aires; BÓGUS, Lúcia; BAENINGER, Rosana. Migrantes e refugiados sul-sul na cidade de São Paulo: trabalho e espacialidades. In: BAENINGER, Rosana et al. (orgs.). Migrações Sul-Sul. Campinas: Núcleo de Estudos de População "Elza Berquó" - Nepo/Unicamp, 2018a, p. 402-419.

MAGALHÃES, Luís Felipe Aires; BÓGUS, Lúcia Maria Machado; BAENINGER, Rosana. Migrantes haitianos e bolivianos na cidade de São Paulo: transformações econômicas e territorialidades imigrantes. REMHU, Revista Interdisciplinar da Mobilidade Humana, v. 26, n. 52, p. 75-94, 2018b.

MAGNANI, José Guilherme Cantor. De perto e de dentro: notas para uma etnografia urbana. Revista Brasileira de Ciências Sociais, v. 17, n. 49, p. 11-29, 2002.

MAMED, Letícia Helena. Haitianos na Amazônia: a morfologia da migração haitiana pelo Acre e o horizonte de inserção precarizada no Brasil. Ruris - Revista do Centro de Estudos Rurais, v. 10, n. 1, p. 73-111, 2016.

MARTES, Ana Cristina Braga; RODRIGUEZ, Carlos L. Afiliação Religiosa e Empreendedorismo Étnico: o Caso dos Brasileiros nos Estados Unidos. Revista de Administração Contemporânea, v. 8, n. 3, p. 117-140, jul./set. 2004.

MAUSS, Marcel. Ensaio sobre a dádiva. Forma e razão da troca nas sociedades arcaicas. In: Sociologia e Antropologia, v. II, São Paulo: Edusp, 1974.

PEREIRA, Alexandre Branco. Viajantes do tempo: imigrantes-refugiadas, saúde mental, cultura e racismo na cidade de São Paulo. Curitiba: CRV, 2020.

PIMENTEL, Marília; COTINGUIBA Geraldo Castro. Wout, raketè, fwontyè, anpil mizè: reflexões sobre os limites da alteridade em relação à imigração haitiana para o Brasil. Universitas Relações Internacionais, v. 12, n. 1, p. 73-86, jan./jun. 2014.

SÃO PAULO (prefeitura). Acolhimento para imigrantes. 14 nov. 2019. Disponível em: $<$ https://www.prefeitura.sp.gov.br/cidade/secretarias/direitos_humanos/imigra ntes_e_trabalho_decente/crai/index.php?p=186982 >. Acesso em: 14.02.2021.

SÃO PAULO (prefeitura). Decreto de lei no 54.156, de 01 de agosto de 2013. Regulamenta os artigos 34 e 35 da Lei no 15.764, de 27 de maio de 2013, que dispõem sobre a criação, composição e atribuições do Conselho Participativo Municipal em cada Subprefeitura. São Paulo. Disponível em: <https://www.prefeitura.sp.gov.br/cidade/ secretarias/subprefeituras/upload/vila_maria_vila_guilherme/decretolei54156. pdf>. Acesso em: 14.02.2021.

SASSEN, Saskia. Sociologia da globalização. Porto Alegre: Editora ARTMED, 2010.

SILVA, Carlos Freire da. Trabalho Informal e Redes de Subcontratação: Dinâmicas Urbanas da Indústria de Confecções em São Paulo. Dissertação de Mestrado. Faculdade de Filosofia, Letras e Ciências Humanas da Universidade de São Paulo, São Paulo, 2008.

SILVA, Sidney Antonio. Imigração e redes de acolhimento: o caso dos haitianos no Brasil. Revista Brasileira de Estudos de População, v. 34, n. 1, p. 99-117, jan.-abr. 2017.

SILVA, Filipe Rezende; LIMA, Cássio Francisco; FERNANDES, Duval Magalhães. Um panorama geral dos imigrantes: haitianos, congoleses, senegaleses e ganeses - da origem ao destino. In: BAENINGER, Rosana et al. (orgs.). Migrações Sul-Sul. Campinas: Núcleo de Estudos de População "Elza Berquó" - Nepo/Unicamp, 2018, p. 420-433. 
TELLES, Vera da Silva. Trajetórias urbanas: fios de uma descrição da cidade. In: TELLES, Vera da Silva; CABANES, Robert (orgs.). Nas tramas da cidade: trajetórias urbanas e seus territórios. São Paulo: Associação Editorial Humanitas, 2006.

Veja os bairros com os metros quadrados mais caros e mais baratos em SP. Portal Economia Uol, 03.05.2013. Disponível em: <https://economia.uol.com.br/ noticias/infomoney/2013/05/03/veja-os-bairros-com-os-metros-quadrados-maiscaros-e-mais-baratos-em-sp.htm?cmpid=copiaecola e https://www.fipe.org.br/ptbr/home > . Acesso em: 14.02.2021.

TRUZZI, Oswaldo. Redes em processos migratórios. Tempo Social, Revista de Sociologia da USP, v. 20, n. 1, p. 199-218, junho de 2008.

VILLEN, Patrícia. O estigma da ameaça ao emprego pelos periféricos na periferia: crise e imigração no Brasil. RUA - Revista do Laboratório de Estudos Urbanos do Núcleo de Desenvolvimento da Criatividade, v. 1, n. 21, p. 247-264, nov. 2015.

ZELAYA, Silvia. A mobilização de refugiados e suas linguagens. Notas etnográficas sobre um campo de interlocução em transformação. Cadernos de Campo, São Paulo, n. 25, p. 400-420, 2016. 